\title{
The relationship between perceived quality and divulgation strategies of products in the electronic marketplace
}

\author{
João Costa ${ }^{\mathrm{a}, *}$ and Milton Horn ${ }^{\mathrm{b}}$ \\ ${ }^{a}$ Graphic Design Post-Graduate Program / Center of Communication and Expression/Centro de Comunidação e \\ Expressão - CCE / Universidade Federal de Santa Catarina - UFSC / Florianópolis, SC Brasi \\ ${ }^{\mathrm{b}}$ Graphic Design Post-Graduate Program / Center of Communication and Expression/Centro de Comunidação e \\ Expressão - CCE / Universidade Federal de Santa Catarina - UFSC / Florianópolis, SC Brasi
}

\begin{abstract}
This article introduces concepts regarding management design, the electronic marketplace and recommendation systems, as well as uses a revised bibliography proposing the relationship between applied management design strategies and recommendation products identified through Cazella [6] and the different types of perceived quality developped by Michalos and Schwartz.
\end{abstract}

Keywords: Management design; e-Commerce; Recommendation systems; Informatic Ergonomics

*Author e-mail: joao@joaocosta.com 


\section{Introduction}

In Brazil, the growth of e-Commerce reached more than $40 \%$ in the year 2010 [6], which reflects the actual expanding and inclusive reality of the Internet, in proportion to everyday usage and access of information for new forms of consumerism.

\section{Quality of the Experience and Recommendation Strategies}

One of the main challenges for a recommendation system in an environment of e-Commerce is to proportionally regulate the increase of profits through

user loyalty [2], for these challenges, Iida [4], highlights that this decision is one of the most common intellectual activities made by human beings, by presenting a varying degree of complexity and important involved factors.

In this manner, the sociologist Alex Michalos [5], examines the perceived quality of the comparison experience, by affirming that people establish comparison patterns in the following three gaps:

- the gap between what a person has and what they want to have;

- the gap between what a person has and what they think people equal to them have, and,

- the gap between what a person has and what they had that was better in the past.

For this reason, a great part of an individual's oscilating satisfactory perception with life can be related, not only to differences in objective experience, but to differences in the three perceived gaps. This comparison made by Schwartz [5] presupposes a fourth possibility, which would be: the gap between what a person has and their expectations.

Cazella [2] demonstrates the following strategies: the reputation of the product, the recommendation by association, the recommendation by content and sequence analysis of actions.

\section{The Relationship between Recommendation Strategies and Comparison Patterns}

\subsection{The Reputation of the Product}

The usage of user assessments to establish the reputation of an item, includes two distinct gaps, between what the person has and what they think people equal to them have, and what the person has and their expectations. Hence using this strategy of reasoning, the user totally bases themself on the relationship of experiences of other people who already have the desired product of their choice.

\subsection{Relationship by Association}

This strategy is structured on a symbolic plane, where social symbolism is the main reason for a determined product purchase. By observing this strategy, it can be noted that it barely bridges the gap between what a person has and what a person wants to have, as well as the gap regarding what a person has and what they had that was better in the past since, these coming recommendations dealing with these relationships have exposed similar and complementary items, based on the user's necessity.

\subsection{Recommendation by Content}

It is known [2] that the analysis of consumer habits for a user and other users part of this ecosystem aim to identify patterns of complex activity, but that they also enable a relationship between different profiles of consumerism for people and similar social classes.

This observation adresses the evidence against these gaps regarding what a person has and what they want to have. Due to the fact that, the recommending of a product with similar information, is thought to prempt the user to look for similar products. This inferred connection brings about a second gap between what a person has and their expectations, which is not possible for the user to presume what items will be offered for their online interaction, but solely the sentiment of confidence in the online relationship

\subsection{The Analysis of a Sequence of Actions}

The analysis of a sequence of actions, positively includes the items sugggested by Michalos and Schwartz, once the cognitive interpretation of the situation regarding a potential consumer's determined emotional reaction [1] and the establishment of this connection as a factor for items that are not explored often has been done.

\section{Conclusion}

Taking into consideration the marketplace's point of view, the identification of social behaviours 
through interactions between people has always been a factor that is valid and often explored by marketing companies. Identifying the target public and the manner in which a certain type of information shall be disseminated can guarantee high profit margins.

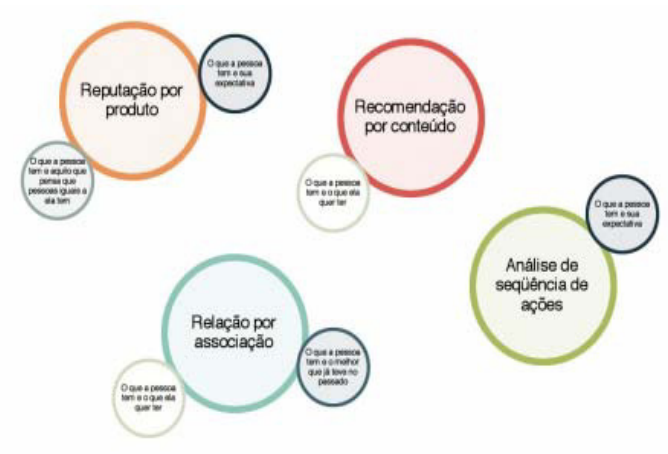

Figure 1 - The Relationship between The Perceived Qualtity and The Main Recommendation Strategies

When dealing with the case of user interaction for informatic ergonomics in e-Commerce, the collaboration of ideas suggested by Padovani and Moura [4], project an interface for design capable of promoting the necessary visual impact for the identification of products exibited to users, by establishing emotional contact and creating a positive attraction.

\section{References}

[1] Borja de Mozota, B; Klöpsch, C.; Costa, F. Gestão do Design. Porto Alegre: Bookman, 2011.

[2] Cazella, S.; Nunes, M.; Reategui, E. A Ciência da Opinião: Estado da Arte em Sistemas de Recomendação. In: André Ponce de Leon F. de Carvalho; Tomasz Kowaltowski.. (Org.). Jornada de Atualização de Informática-JAI 2010- CSBC2010. Rio de Janeiro: PucRIO, 2010, v. 1, p. 161-216.

[3] Padovani, S.; Moura, D.. Navegação em Hipermidia: uma abordagem centrada no usuário - Rio de Janeiro: Editora Ciência Moderna, 2008. 138p.

[4] Schwartz, B. O Paradoxo da Escolha: Por que mais é menos. São Paulo. A Girafa Editora. 2004.

[5] Telebrasil - Associação Brasileira de Telecomunicações. www.telebrasil.org.br. Acesso em: 10 de maio de 2011. 